\title{
Circumstances Associated with Predation Rates on Sheep and Goats
}

\author{
ROGER D. NASS, GREG LYNCH, AND JOHN THEADE
}

\begin{abstract}
Factors possibly associated with high (over $5 \%$ ) and low ( $(0-5 \%)$ predation intensities were compared among 95 sheep or goat producers in $\mathbf{5}$ states to determine if important differences were evident between the 2 groups. Data were compared for the following variables: losses to predation, flock size, type of ranch operation, management practices, predator indices, prey indices, use of U.S. Animal Damage Control program, private control efforts, predation history, timing of predation, and presence of other sheep or goats nearby. Overall, $45 \%$ of the producers reported over $5 \%$ predation losses of their lambs or kids and predation percentages tended to increase with decreased flock sizes. Feeder lamb and range sheep operations had predominantly low predation loss percentages, but most operations that included goats reported over $\mathbf{5 \%}$ predation losses due to goat predation. A variety of management practices were used by both groups; however, low loss producers indicated low natural prey and predator populations. Most of the producers used the federal ADC program and some type of private control effort, although more high loss producers used both types. Rough, bottom, and brush graxing lands, historic predation problems, and high predator indices characterized many of the high loss producers.
\end{abstract}

Predation intensity on livestock among producers is variable (Gee et al. 1977, Nass 1980). Various studies (deCalesta 1978, Schaefer et al. 1981, and others) have shown that livestock losses to predators vary significantly among samples of producers; however, data on reasons for this variability are lacking (Gee et al. 1977). Frequently, experienced animal damage control personnel know or suspect why specific levels of predation are occurring at specific times, but there have been no standardized mechanisms for recording, tabulating, and comparing the information on a ranchby-ranch basis. Boggess et al. 1980, Meduna 1977, and Schaefer et al. 1981 have explored the effects of some husbandry practices on livestock predation levels.

The objective of our study was to identify factors common to ranches with high sheep or goat predation and compare them with low predation loss ranches.

\section{Methods}

Sheep producers in 5 states: California, Idaho, North Dakota, Oregon, and Texas were interviewed to obtain data on their 19791980 sheep or goat operations. Producer names were provided by state sheep associations, county agents, and U.S. Fish and Wildlife Service animal damage control (ADC) district supervisors. Information was collected from 95 sheep or goat producers selected from a total listing of about 300 producers. The list did not include all producers in each state. The sample was selected to include a variety of sheep operations through consultations with people knowledgeable about the sheep and goat industries in each state.

\footnotetext{
Authors are project leader and biologist, U.S. Fish and Wildlife Service, Denver Wildlife Research Center, P.O. Box 593, Twin Falls, Ida. 83303-0593; and biological technician, U.S. Fish and Wildlife Service, Denver Wildlife Research Center, Cynthia Ann Bldg., 322 Main Street, Dallas, Ore. 97338

Manuscript accepted February 7. 1984.
}

Data were collected on the following features:

Losses to predation

Flock size

Type ranch operation

Husbandry practices

Predator index

Natural prey index

General habitat types were determined by observation. Predator and natural prey indices were rated on a 1 to 3 scale indicating low, moderate, and high densities by the producers, sheep foremen, or in some instances, the district field assistants, depending upon familiarity with the specific areas involved.

Because of the large Texas goat industry, 7 of 12 producers from that sample raised goats, either alone or in conjunction with sheep, cattle, or both. The producers were assigned to a low predation loss category $(0-5 \%)$ or a high predation loss category (over $5 \%$ ). This division was used for convenience in making comparisons; from the producers'viewpoint, losses of less than $5 \%$ may be considered excessive and have an adverse economic impact upon their operations.

\section{Results}

Overall, $43(45 \%)$ of the producers incurred over $5 \%$ loss of lambs or kids to predators; $38(40 \%)$ reported over $5 \%$ predation losses when adults were included (Table 1). The percentages of lamb/kid predation were loosely correlated with flock size ( $r=$ $-0.22, P 0.05=0.205$ ). Although there was extreme variation with the sample, percentages of lambs/kids lost to predation tended to

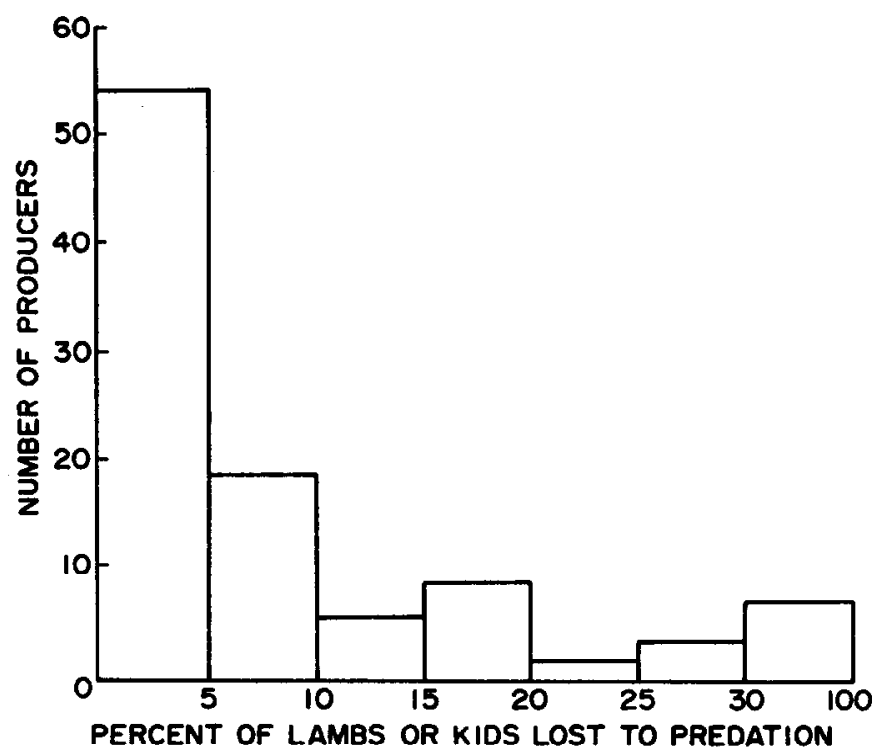

Fig. 1. Intensity of predation on lambs or kids by numbers of producers 
Table 1. Percent of ranchers, by state, with high (over $5 \%)$ or low $(0-5 \%)$ reported predation losses.

\begin{tabular}{|c|c|c|c|c|c|}
\hline \multirow[b]{3}{*}{ Statc } & \multirow{3}{*}{$\begin{array}{l}\text { Number of } \\
\text { ranches (n) }\end{array}$} & \multicolumn{4}{|c|}{ Percent of ranches at each predation rate } \\
\hline & & \multicolumn{2}{|c|}{ Predation on lamb/kids } & \multicolumn{2}{|c|}{ Total sheep/goat predation } \\
\hline & & Low & High & Low & High \\
\hline$\overline{\mathrm{OR}}$ & 35 & 57 & 43 & 54 & 46 \\
\hline ID & 20 & 50 & 50 & 65 & 35 \\
\hline ND & 13 & 23 & 77 & 38 & 62 \\
\hline TX & 12 & 33 & 67 & 42 & 58 \\
\hline CA & 15 & 100 & 0 & 100 & 0 \\
\hline Overall & 95 & 55 & 45 & 60 & $\overline{40}$ \\
\hline
\end{tabular}

Table 2. Mean flock or herd size at five levels of predation intensity (no. of producers in parens).

Levels of reported predation on lambs and kids

\begin{tabular}{|c|c|c|c|c|c|}
\hline \multirow[b]{2}{*}{ State } & \multirow[b]{2}{*}{ None } & \\
\hline & & $0>5 \%$ & $5>10 \%$ & $10>15 \%$ & $15>100 \%$ \\
\hline OR & $389(10)$ & $3146(10)$ & $412(4)$ & $265(1)$ & $330(10)$ \\
\hline TX & - & $912(4)$ & $553(3)$ & - & $494(5)$ \\
\hline ND & $435(2)$ & $1530(1)$ & $670(5)$ & $813(2)$ & 378 (3) \\
\hline ID & $585(2)^{a}$ & $698(7)$ & $761(6)$ & $679(2)$ & $404(2)$ \\
\hline CA & $5591(6)$ & $4561(9)$ & - & - & - \\
\hline Overall $\bar{X}$ & $17 \overline{750(20)}$ & $\overline{2169(31)}$ & $\overline{599(18)}$ & $\overline{586(5)}$ & $\overline{401(20)}$ \\
\hline
\end{tabular}

"One flock with no lambs excluded.

increase as flock size decreased. Twenty producers did not suffer predation losses whereas 20 lost over $15 \%$ of their lambs/kids to predation (Table 2). The predation loss distribution by numbers of producers is shown in Figure 1.

The feeder type operations in Oregon and some California producers had large flocks of sheep, thereby increasing mean flock sizes for those states. The mean number of sheep or goats per low-loss producer was 1,875 , but this dropped to 703 when the California sample was excluded. The mean number of animals for high-loss producers remained at 560 with and without the California producers.

The types of farm or ranch operations fit seven general categories (Table 3). Forty-four percent of the sheep producers had farm

Table 3. Percentages of 95 producers by type of operation and predation intensity.

\begin{tabular}{lccc}
\hline \hline & $\begin{array}{c}\text { Percent of producers } \\
\text { with lamb or kid } \\
\text { predation rates }\end{array}$ & $\begin{array}{l}\text { Percent of } \\
\text { producers }\end{array}$ \\
\cline { 2 - 3 } Type operation & $0-5 \%$ & over 5\% & \\
Farm flock & 45 & 55 & 44 \\
Sheep-cattle & 61 & 39 & 19 \\
Sheep & 65 & 35 & 18 \\
Sheep-cattle-goat & 29 & 71 & 7 \\
Range flock & 83 & 17 & 6 \\
Feeder lamb & 100 & 0 & 3 \\
Goat-cattle & 50 & 50 & 2 \\
\hline
\end{tabular}

flocks that usually contained less than 300 sheep. Most combined raising sheep with other types of farming or ranching, such as growing of row or forage crops. A majority, $55 \%$ of these producers lost over $5 \%$ of their lambs or kids to predation. Although the sample is small, most producers ( $71 \%$ ) with sheep, cattle, and goats lost over $5 \%$ of their lambs or kids to predation. No feeder lamb operations lost over $5 \%$ of the lambs to predation. Sheep, sheepcattle, and range flock operations, constituting $43 \%$ of the sample, generally had less than $5 \%$ loss to predators.

Sheep management (husbandry practices) techniques were arbitrarily separated from use of control methods, although some could appear in either or both lists. For example, the use of electric fencing to exclude coyotes might be considered either a control method or a management practice, as could the use of guard dogs, woven wire fences, and others. The husbandry practices list includes items for which information was available, but does not necessarily include every possible management practice used by every producer (Table 4). Rotation of pastures, use of two herders, and night lighting are examples of practices for which information was not obtained.

Among the 95 producers, use of woven wire fencing $(100 \%)$, shed lambing (79\%), and daily sheep checking $(66 \%)$ were the most frequently used management practices. Range flock producers used woven wire fences on home ranches, but of course did not use woven wire on open ranges. Producers using these three husbandry techniques were about equally divided between high and low predation on lambs or kids with over $5 \%$ losses incurred by $45 \%$ of those with woven wire fences, by $47 \%$ that shed lambed, and by $46 \%$ who checked their sheep daily. Keeping sheep close to buildings at night, penning at night, and using herders were the next most prevalent management techniques noted. Most producers who penned sheep at night and used herders had low losses to predators. Thirty-nine producers $(41 \%)$ were using one or more of these techniques in their sheep or goat management. Keeping sheep close to buildings at night and penning at night were used for smaller farm flocks, whereas herders were used with larger flocks in fenced pastures or on open range. Other practices, such as confinement of lambs, bells on sheep, and predator proof electric fencing were reported infrequently.

Producers' impressions of predator and natural prey abundance showed lower indices for both prey (2.1) and predators (2.2) from those ranches with low predation rates. Reports of higher natural prey (2.3) and predator (2.6) indices came from high-predation- 
Table 4. Use of some management techniques among 95 producers in relation to predation rates.

\begin{tabular}{|c|c|c|c|c|c|}
\hline \multirow[b]{3}{*}{ Management technique } & \multicolumn{3}{|c|}{ Lamb/kid predation class } & & \multirow{3}{*}{$\begin{array}{c}\text { Total producer } \\
\text { use }(\%)\end{array}$} \\
\hline & \multicolumn{2}{|c|}{$0-5 \%$} & \multicolumn{2}{|c|}{$>5 \%$} & \\
\hline & No. producers & $\%$ & No. producers & $\%$ & \\
\hline Use of woven wire fences & 52 & 55 & 43 & 45 & 100 \\
\hline Use shed lambing & 40 & 53 & 35 & 47 & 79 \\
\hline Check sheep daily & 34 & 54 & 29 & 46 & 66 \\
\hline Keep sheep close to barn at night & 9 & 47 & 10 & 53 & 20 \\
\hline Pen at night & 8 & 73 & 3 & 27 & 12 \\
\hline Use herders & 8 & 89 & 1 & 11 & 9 \\
\hline Confine lambs & 2 & 67 & 1 & 33 & 3 \\
\hline Use bells on sheep & 3 & 100 & 0 & 0 & 3 \\
\hline Use goats with sheep & 1 & 50 & 1 & 50 & 2 \\
\hline Move sheep after predation & 1 & 100 & 0 & 0 & 1 \\
\hline Use predator electric fence & 0 & 0 & 1 & 100 & $i$ \\
\hline Reduce sheep numbers & 1 & 100 & 0 & 0 & 1 \\
\hline
\end{tabular}

loss ranches. Mean indices for all ranches were 2.2 for prey species and 2.4 for predators.

Most producers used some type of animal damage control (Table 5), either private (self or contract) or through the U.S. Fish and Wildlife Service Animal Damage Control program. Only three producers did not use any program or methods for depredation reduction. Among low loss producers, $88 \%$ used the federal program and $67 \%$ carried out private control of some type. The federal program was used by $98 \%$ of the higher loss producers and $93 \%$ of these added private control efforts of some type.

Shooting coyotes was the most common form of private control work done by all produccrs $(60 \%)$. This included attempts to shoot coyotes, calling or actively looking for coyotes, and incidental shooting when coyotes or dogs were observed during routine ranching activities. Personal trapping (11\%), hiring trappers $(5 \%)$, and hiring helicopters for aerial gunning $(5 \%)$ were the next three popular forms of private control (Table 5). Use of guard dogs, hunting with snowmobiles, and shooting dogs were each reported by $3 \%$ of the producers. Producers with high predation losses used more methods and were more active in using private control efforts than were the producers with low losses.

Areas that are unsuitable for other purposes are frequently used for grazing sheep and goats. This is reflected in our sample where $46(48 \%)$ of the producers used a combination of rough, bottom, and brush lands for their sheep or goats. Another $13(14 \%)$ had similar areas adjacent to or near their ranches. Nine $(21 \%)$ highloss producers, but only $4(8 \%)$ low-loss producers, had rough terrain and bottom areas adjacent to or near their grazing areas. Combinations of brush, timber, and grass or brush, and pasture made up grazing areas for $21(22 \%)$ of the producers and included $12(23 \%)$ of the low loss producers and $9(19 \%)$ of the high loss producers. Open type (mainly grass) pastures were utilized by 12 $(23 \%)$ and $3(7 \%)$ of the low- and high-loss producers, respectively. When only considering those 19 producers with no predation of lambs, $7(37 \%)$ used open type, mainly grass, pastures, $9(47 \%)$ used pastures with predominant brush or timber, and $3(16 \%)$ used rough, bottom, and brush land. Two of these last three producers raised their lambs in confinement because of historic heavy predation, but they did allow ewes to graze the rugged pastures.

Predation history assessment by producers tended to follow current predation loss problems. Some low-loss producers assessed historical predation as high (56\%), and others as low (24\%). Eighty-four percent with high losses indicated predation was high historically, and only $2 \%$ had minor predation losses previously. Other producers cited yearly fluctuations in predation, extenuating circumstances related to predation, or varying predation rates related to yearly control efforts.

Most predation for low loss producers (45\%) occurred during March, April, and May; however, $31 \%$ indicated predation could occur any time while the sheep or goats were grazing. Higher-loss producers also said losses could occur any time while animals were grazing (28\%), but their high-loss months were April, May, and June (37\%). Overall, $46 \%$ of the sample indicated that March through June were the months when predation could be severe.

Only 5 of 95 producers raised sheep or goats in isolation from other flocks or herds; therefore, the sample size was too small for speculation on the importance of this factor.

Table 5. Use of private predation control methods by 95 sheep/goat producers in relation to predation rates.

\begin{tabular}{|c|c|c|c|c|c|}
\hline \multirow[b]{3}{*}{ Control method } & \multicolumn{3}{|c|}{ Lamb/kid predation class } & & \multirow{3}{*}{$\begin{array}{c}\text { Total producer } \\
\text { use }(\%)\end{array}$} \\
\hline & \multicolumn{2}{|c|}{$0-5 \%$} & \multicolumn{2}{|c|}{$>5 \%$} & \\
\hline & No. producers & $\%$ & No. producers & $\%$ & \\
\hline Shoot coyotes & 24 & 25 & 33 & 35 & 60 \\
\hline Trap coyotes & 4 & 4 & 6 & 6 & 11 \\
\hline Hire trapper & 3 & 3 & 2 & 2 & 5 \\
\hline Hire helicopter & 3 & 3 & 2 & 2 & 5 \\
\hline Use guard dogs & 1 & 1 & 2 & 2 & 3 \\
\hline Hunt with snowmobile & 1 & 1 & 2 & 2 & 3 \\
\hline Shoot dogs & 3 & 3 & 0 & 0 & 3 \\
\hline Use hounds & 0 & 0 & 2 & 2 & 2 \\
\hline Pay bounty & 0 & 0 & 1 & 1 & 1 \\
\hline Use poison & 0 & 0 & $i$ & 1 & 1 \\
\hline Use no private control & 17 & 18 & 3 & 3 & 21 \\
\hline
\end{tabular}




\section{Discussion}

The distribution of losses to predation in our sample is similar to those shown by Boggess et al. 1978, Dorrance and Roy 1976, Schaefer et al. 1981, and others. The tendency of producers with fewer animals to lose greater percentages of their sheep or goats than those with larger flocks might indicate that substantial differences occur in predator control policies between small and large operations. This does not appear to be true for the various features possibly affecting predation that werc examined in our study, even though modes of operation generally differed with flock size. Overall, private control efforts, federal control efforts, general managerial practices, and other factors were similar between the large and small operations.

Range flock and feeder lamb operations had low predation loss percentages; however, some still reported large losses to predators. Feeder lamb producers usually restrain their flocks in confinement or semiconfinement and have close control over their flocks; both types of production are suited to large flocks. Ranches that included goats and farm flocks had higher predation loss percentages than did other types of operations. Goats are frequently raised in isolated pastures and are subject to severe predation in the brush areas of Texas (Wade 1982). Because farm flocks have modest numbers of animals, one or a few incidences of severe predation may result in substantial impact upon these producers. Even though loss percentages were low, most producers with predation problems and large flocks lost more animals to predation than did those with smaller flocks.

The four most widely used husbandry techniques were practiced about equally by producers with high and low predation losses. Penning at night and using herders were associated with low loss percentages; however, only $12 \%$ and $9 \%$, respectively, of the total sample utilized these techniques. Davenport et al. (1973) found that Utah sheep producers using herders might have significant predation losses, but those losses were lower than for producers who did not use herders. Predation, in our sample, did not seem to be directly related to specific husbandry techniques. Husbandry practices are most efficient when used in conjunction with lethal control methods and their usefulness may be related to effort expended on such methods.

Most high-loss producers used the federal animal damage control program, utilized some form of private control, and indicated that predator and natural prey populations were relatively dense.

Persistent predation problems tend to generate increased efforts for predation reduction; therefore, it is not surprising that highloss producers made extensive use of the federal animal damage control program. A similar situation existed for private control method efforts; increased predation resulted in the use of more mcthods in attempts to stop or reduce predation losses. Private control efforts were not used by 17 of the low loss producers, presumably because their predation problems or lack of them did not warrant the expense. Predator and prey index assessments indicated more coyotes or coyote signs and natural prey species or signs were seen on ranches with higher predation levels. This index was not precise, reflecting only general observations; thus, ranchers with high losses may have only assumed that coyotes were abundant. A pair or two of coyotes can kill many lambs or kids, especially when litter energy demands are high (Till and Knowlton 1982), thus giving an impression of numerous coyotes present.

High-loss producers grazed animals in rough, bottom, or brush areas, or had these types close by $(72 \%)$ in more instances than did low loss producers $(53 \%)$. Generally, predation losses tended to be low for open, grassy, grazing areas. Frequently, habitats with dense vegetation and broken landscape contain large numbers of prey species, thus hold greater numbers of predators than do open areas. Control efforts may also be hampered by dense vegetation and rough terrain by restricting foot, horse or vehicular access and limiting the efficiency of aerial shooting. Historically, predation on many ranches varied from year to year, but higher predation losses were reported on ranches with a high-predation-loss history.

Most predation occurred in spring when lambs or kids were available in large numbers and when predators are typically provisioning young. Younger animals are most susceptible to predation; frequently the remains of small carcasses are not easily detected, therefore the predation of young animals may be difficult to detect and remedy.

Suitable terrain for predators, historic loss patterns, and higher predator indices tended to be associated with increased percentages of lambs or kids lost to predation. Surely, a combination of other factors is also involved: for example, the management practices and control efforts on adjacent ranches, the quality of husbandry and depredation control, and the relative abundance of resident coyotes.

\section{Literature Cited}

Boggess, E.K., R.D. Andrews, and R.A. Bishop. 1978. Domestic animal losses to coyotes and dogs in Iowa. J. Wildl. Manage. 42:362-372.

Boggess, E.K., F.R. Henderson, and C.W.Spaeth. 1980. Managing predator problems: practices and procedures for preventing and reducing livestock losses. Kansas State Univ. Coop. Ext. Ser. Rep. C-620.

Davenport, J.W., J.E. Bowns, and J.P. Workman. 1973. Assessment of sheep losses to coyotes-a problem to Utah sheepmen-a concern of Utah researchers. Utah Agr. Exp. Sta. Res. Rep. 7.

deCalesta, D.S. 1978. Documentation of livestock losses to predators in Oregon. Oregon State Univ. Ext. Ser. Rep. 501.

Dorrance, M.J. and L.D. Roy. 1976. Predation losses of domestic sheep in Alberta. J. Range Manage. 29:457-460.

Gee, C.K., R.S. Magleby, W.R. Bailey, R.L. Gum, and L.M. Arthur. 1977. Sheep and lamb losses to predators and other causes in the western United States. USDA Agr. Econ. Rep. 369.

Meduna, R.L. 1977. Relationships between sheep management and coyote predation. M.S. Thesis, Kansas State Univ., Manhattan.

Nass, R.D. 1980. Efficacy of predator damage control programs. Proc. Ninth Vertebrate Pest Conf. March 4-6, Fresno, Calif.

Schaefer, J.M., R.D. Andrews, and J.J. Dinsmore. 1981. An assessment of coyote and dog predation on sheep in southern lowa. J. Wildl. Manage. 45:883-893.

Till, J.A., and F.F. Knowlton. 1982. Efficacy of denning in alleviating coyote depredations upon domestic sheep. J. Wildl. Manage. 47:10181025.

Wade, D.A. 1982. Impacts, incidence and control of predation on livestock in the United States, with particular reference to predation by coytes. Council Agr. Sci. and Tech., No. 10. 